\title{
CONTEÚDO JURÍDICO DO VALOR SOCIAL DO TRABALHO: PRESSUPOSTOS NORMATIVO- CONSTITUCIONAIS DA COMPLEMENTARIDADE ENTRE O DIREITO DO TRABALHO E O DIREITO AO TRABALHO
}

\author{
Jailton Macena de Araújo ${ }^{1}$
}

Resumo: A Constituição Federal de 1988 desempenha importante papel na estruturação da questão social, funcionando como frente de resistência à crise democrática que se atravessa atualmente. Muitos dos direitos e valores nela assegurados ainda carecem de efetividade, especialmente os direitos sociais são ainda alvo de ataques que tem levado a uma profunda precarização principalmente das relações laborais. É, nesse sentido, que se pretende analisar o papel e as acepções do valor social do trabalho, valor fundante da república e condição máxima para a promoção da inserção humana, como verdadeira frente de resistência aos retrocessos sociais. Assim, impõe-se o seguinte problema: é possível reconhecer o valor social do trabalho como elemento fundante da centralidade normativa do trabalho no pacto desenvolvimentista fundado com a Constituição de 1988? Pretende-se, pois, a partir da análise metodológica sistêmica, defender que é através do trabalho que se percebem os benefícios da participação nos resultados do desenvolvimento, especialmente quando postas em prática de maneira eficaz as diretrizes do direito do trabalho e do direito ao trabalho, como faces complementares para a promoção da cidadania, pautada no desenvolvimento e na realização da dignidade da pessoa humana e que garante os meios e pressupostos para objetar os contrafluxos neoliberais.

Palavras-chave: Valor social do trabalho. Direito do trabalho. Direito ao trabalho. Resistência. Precarização.

LEGAL CONTENT OF THE SOCIAL VALUE OF WORK: NORMATIVE AND CONSTITUTIONAL ASSUMPTIONS OF THE COMPLEMENTARITY BETWEEN THE LAW OF LABOR AND THE RIGHT TO WORK

\footnotetext{
${ }^{1}$ Doutor em Ciências Jurídicas, área de concentração Direitos Humanos e Desenvolvimento, pela Universidade Federal da Paraíba (2016), mestre em Ciências Jurídicas, área de concentração em Direito Econômico, pela Universidade Federal da Paraíba (2011) e graduado em Direito pela Universidade Federal de Campina Grande (2007). Professor Permanente do Programa de Pós-Graduação em Ciências Jurídicas. Docente do Curso de Direito, vinculado ao Departamento de Direito Processual e Prática Jurídica (DDPPJ), do Centro de Ciências Jurídicas (CCJ) da Universidade Federal da Paraíba. Atualmente é Editor Gerente da Prim@ Facie (Revista do PPGCJ). Lattes: http://lattes.cnpq.br/7244831858426121 .Instituição: Universidade Federal da Paraíba. Brasil. E-mail: jailtonma@gmail.com
} 
Abstract: The Federal Constitution of 1988 plays an important role in structuring the social issue, functioning as a front of resistance to the current democratic crisis. Many of the rights and values insured there still lack effectiveness, especially social rights are still the target of attacks that have led to a deep precariousness mainly of labor relations. It is in this sense that we intend to analyze the role and meanings of the social value of work, the founding value of the republic and the maximum condition for the promotion of human insertion, as a true front of resistance to social setbacks. Thus, the following problem is posed: Is it possible to recognize the social value of labor as a foundational element of the normative centrality of labor in the developmental pact founded with the 1988 Constitution? It is intended, therefore, from the systemic methodological analysis, to defend that it is through work that the benefits of participation in development outcomes are perceived, especially when the guidelines of labor law and the right to work are effectively implemented, as complementary faces for the promotion of citizenship, based on the development and attainment of the dignity of the human person and which guarantees the means and presuppositions to object to neoliberal counterflows.

Keywords: Social value of work. Labor law. Right to work. Resistance. Precariousness.

\section{Introdução}

A Constituição Federal de 1988 desempenha muitos papéis relacionados à estruturação da questão social no Brasil, funcionando também de frente de resistência à crise democrática que se atravessa atualmente.

Dentre os inúmeros papéis desempenhados pelo texto constitucional, a sua dialeticidade e a sua conformidade à valores múltiplos acaba por proporcionar na realidade social muitos anseios ainda pendentes de realização, intensamente obstaculizados pelos contrafluxos neoliberais, que nos últimos anos vem se intensificando e provocando ainda maiores contrassensos e retrocessos.

A realidade social brasileira ainda almeja efetividade à Constituição de 1988, especificamente no que se refere aos direitos sociais e na repercussão desses direitos em políticas e ações de inserção social e econômica, ligadas efetivamente ao desenvolvimento. E ainda assim, ataques a esses direitos são implementados diuturnamente, promovendo uma precarização ainda agressiva aos direitos dos trabalhadores.

É, nesse sentido, por ligar-se ao desenvolvimento e às questões sociais, que o trabalho se impõe como valor fundante da república e condição máxima para a promoção da inserção humana que se coloca, embora tolhido na sua eficácia normativa, a principal frente de resistência aos retrocessos 
sociais ligados aos direitos sociais. É através do trabalho que se percebem os benefícios da participação nos resultados do desenvolvimento, muito embora, apesar do seu reconhecimento como instrumento de liberação humana e emancipação cidadão, o trabalho seja ainda um dos mais atingidos pela crise social.

Apenas o trabalho, protegido e digno, pode promover ao ser humano a condição de partícipe pleno da sociedade. Dessa maneira, o exercício da cidadania apenas é efetivo quando a participação na realização do desenvolvimento ocorre em sua plenitude. É nesse sentido que se coloca a questão que conduz o presente texto: é possível reconhecer o valor social do trabalho como elemento fundante da centralidade normativa do trabalho no pacto desenvolvimentista fundado com a Constituição de 1988 ?

Pretende-se, pois, a partir da análise metodológica sistêmica, avaliar o contexto constitucional no qual se insere o valor social do trabalho, como consectário das perspectivas relativas ao "direito ao trabalho" e ao "direito do trabalho", como faces complementares para a promoção da cidadania, pautada no desenvolvimento e na realização da dignidade da pessoa humana e que garante os meios e pressupostos para objetar os contrafluxos neoliberais, que tem contribuído de modo cada vez mais grave para a precarização dos direitos e da vida humana.

Estrutura-se o texto, portanto em seções, as quais pretendem abordar a centralidade do trabalho como instrumento de promoção da dignidade humana, a pressuposição normativa da complementaridade entre o direito do trabalho e o direito do trabalho, os quais de forma sistêmica, afluem para a garantia efetiva do valor social do trabalho como elemento fundante da ordem jurídica brasileira e principal fonte normativa de resistência aos contrafluxos neoliberais.

2 Direito do trabalho em tempos de crise: a desconstrução da acepção protetiva do valor social do trabalho

Como se pretende apresentar ao longo do texto, decorrem do valor social do trabalho, constitucionalmente assegurado, duas acepções distintas, porém complementares, da proteção social e do acesso ao trabalho.

Reconhece-se então, que da positivação constitucional do trabalho decorrem alguns parâmetros mínimos para a consecução dos objetivos constitucionais no sentido da construção de uma sociedade livre, justa e solidária, da promoção do desenvolvimento nacional, da redução das desigualdades regionais e socais e para a erradicação da pobreza.

É a partir do estabelecimento destes objetivos constitucionais do Estado brasileiro que se pode 
afirmar que é a partir do trabalho, por meio da esfera normativa, que se verifica a configuração dos fatores que entrelaçam e proporcionam, em benefício da realização da cidadania, o direcionamento das ações públicas (do Executivo, Legislativo e Judiciário) no sentido da consecução dos meios para a existência digna. Ainda, esses mesmos objetivos funcionam também como princípios fundamentais, de ordem programática e progressiva, como meios para determinação das políticas públicas, e também, principalmente, como pontos de resistência normativo-democrática às investidas neoliberais contra os direitos sociais.

Desta forma, a medida que orientam para as ações programáticas, em direção ao desenvolvimento, funcionam também como freios às ações tendentes a retirar direitos. É, exatamente nesta perspectiva de promoção e proteção à consecução dos objetivos constitucionais, que o trabalho se insere como meio de concretização. O trabalho, enquanto ação humana valorada, é a diretriz para a inserção normativa do valor social do trabalho (e os seus desdobramentos) na esfera constitucional.

Nessa medida, o "direto do trabalho" e o "direito ao trabalho", decorrentes da superestrutura constitucional, pautada no "valor trabalho", são reconhecidos como paradigmas valorativos e normativos que decorrem, respectivamente, da proteção e do acesso ao trabalho², abrangidos pelo fundamento constitucional "valor social do trabalho".

Historicamente, no limiar do surgimento da ideia de cidadania, como uma conquista dos camponeses em face do absolutismo monárquico que culminou com a Revolução Gloriosa no século XVII, fundou-se o liberalismo como marco ideológico. Com a agudização da exploração do trabalho dos sujeitos sociais, a partir do marco liberal-burguês, a Revolução Industrial trouxe à luz a classe operária, num movimento de luta pelo reconhecimento de direitos.

Entretanto, foi com a Revolução Francesa, em 1789, que houve a verdadeira expansão dos horizontes do pensamento liberal, afastando os obstáculos políticos feudais que ainda impediam a expansão máxima do pensamento iluminista. Após a Revolução Francesa, o ideário liberal de "liberdade, igualdade e fraternidade" expande-se para o mundo, determinando e ampliando a compreensão não apenas de cidadania, mas de proteção aos direitos do homem como decorrência da sua própria condição.

Surgiu então o direito do trabalho, nascido com a Revolução Industrial, intimamente ligado ao desenvolvimento do modo de produção capitalista dela decorrente. O direito do trabalho teria, então, desde o seu surgimento, a função primordial da proteção dos trabalhadores em face da relação de emprego firmada com os donos do capital. Isto porque, se admite que "[...] devido à relação de

\footnotetext{
2 Pretende-se, portanto, sistematizar - não com caráter de definitividade - as abordagens acerca da compreensão do direito do trabalho e do direito ao trabalho, apresentando algumas acepções e peculiaridades inerentes às expressões, que as reportam distintas, mas também complementares e, em alguns pontos, semelhantes.
} 
dependência, o direito do trabalho visa proteger o trabalhador contra a arbitrariedade do empregador e reequilibrar as suas relações ${ }^{3}$ (LA TOUPIE, 2015)".

No contexto hodierno, o direito do trabalho, decorrente do valor social do trabalho garantidos na constituição exerce função semelhante, conferindo um sentido estabilizador das relações sociais, no contexto capitalista. Nas palavras de Rüdiger:

O direito do trabalho é filho da modernidade, pois veio dar forma à relação de emprego moderna que se desenvolve junto ao mercado. Mais do que isso, o direito do trabalho constitui um elemento estabilizador da sociedade capitalista, porque se, de um lado, o mercado implica a constante destruição do antigo, do tradicional e do permanente, de outro lado, também produz o novo, o estável, tanto no plano material quanto no plano das ideias (RÜDIGER, 2004, p. 38).

O direito do trabalho apresenta, então, a peculiaridade de estar situado no âmbito do direito constitucional econômico, no limiar dos ramos do direito público e do direito privado. No seu bojo são expressas normas de caráter cogente, com claro teor protetivo do trabalhador/empregado na relação de trabalho ${ }^{4}$, além de apresentar outras regras que podem ser avençadas, com certo grau de liberdade, entre os contratantes (empregador e empregado).

Ambos os sujeitos do contrato de trabalho estão conjugados em relação ao Estado e aos agentes de mercado (capital), em prol de um interesse social maior que é a produção dos bens necessários à subsistência da sociedade. O direito do trabalho convive, assim, de modo satisfatório, embora sujeito às intempéries e dissensos, com as instâncias e ações de teor democrático, sendo exercido cotidianamente nas esferas da produção de bens de consumo e da prestação de serviços, realizados em troca de uma prestação onerosa e, em regra pecuniária, que serve de remuneração para o trabalhador. Desta maneira, o direito do trabalho consumou-se, nos dizeres de Delgado (2006, p. 1.161) "[...] como um dos mais eficazes instrumentos de gestão e moderação de uma das mais importantes relações de poder existentes na sociedade contemporânea, a relação de emprego".

O primeiro foco na ação dos entes estatais e, em alguns casos de organismos internacionais

\footnotetext{
3 Tradução do autor. No original: "Du fait de la relation de dépendance, le droit du travail cherche à protéger le salarié contre l'arbitraire de l'employeur et à rééquilibrer leurs relations".

${ }^{4}$ Há de se deixar claro, apesar da afirmação, que o paradigma protetivo do direito do trabalho foi subvertido quase que completamente com a edição da Lei n. 13. 467 de 2017, a chamada Reforma Trabalhista. A partir da Reforma o paradigma protetivo foi reestruturado e modificado para uma compreensão muito mais privatista das relações laborais. A autonomia da vontade foi colocada como patamar de definição das regras a serem observadas na relação de emprego, trabalhadores que receberem a partir de determinado limite terão a livre possibilidade de negociar diretamente com seus empregadores (art. 444, Parágrafo único, CLT), bem como será observada em todas as mais amplas esferas (especialmente do Judiciário Trabalhista) a livre manifestação da vontade coletiva (art. 8으, §3으, CLT), desvirtuamento claro à feição protetiva e conformadora do direito do trabalho, no sentido de resguardar direitos assegurados na lei.
} 
(como é o caso da OIT), em prol do direito do trabalho, ocorreu em razão de suas vinculações com o mercado, no intuito de se gerarem benefícios sociais como desdobramento do crescimento econômico advindo da estabilização da mão-de-obra. Por essa razão, o direito do trabalho é detentor de um conjunto de princípios e regras próprios que regulam as relações empregatícias, ou em outras categorias econômicas, interagindo com o direito ao trabalho, em prol da participação do cidadão trabalhador na chamada democracia econômica, que é pautada na regulação dos direitos laborais.

Acerca da instrumentalização pelo direito do trabalho, pode-se afirmar que, embora esteja inserido no mesmo cenário, fundado na globalização e na inserção no capital, persiste como foco de resistência e proteção. O direito do trabalho convive, pois, lado a lado com as tentativas de sua precarização. Dessa forma, a regulação dos direitos laborais é compreendida, a prioiri, em seu viés protetivo, como um dos pilares do valor social do trabalho e se refere ao arcabouço jurídico, existente na maior parte do Ocidente, para proteção do trabalhador. Por outro lado, é o direito do trabalho o primeiro ramo jurídico a sofrer as investidas neoliberais no sentido da precarização das relações humanas da maximização dos lucros para o mercado.

As condições laborais contam, assim, com o suporte de um padrão mínimo de decência nas relações que se estabelecem entre tomador e prestador de serviços, sendo essas mesmas relações as responsáveis por deteriorar o campo dos direitos sociais em momentos de crise. Todavia, é o estabelecimento da decência do trabalho que reflete o ideário de cidadania, exigindo a efetividade e a proteção estatais. Essa realização torna factíveis as dimensões do desenvolvimento, no qual a proteção do trabalho se insere.

Fica claro, pois, que o valor social do trabalho passa a constituir o valor guia dos direitos sociais, econômicos e culturais, a partir da compreensão da igualdade como norte primordial dos direitos laborais, cujo fundamento é a atuação estatal. Nesse esteio, é evidenciada a dignidade da pessoa humana enquanto instrumento para a realização dos direitos sociais e que tem como base a centralidade do trabalho e sua proteção.

É pelo que se observa que o direito do trabalho é o ramo do direito que melhor se insere no surgimento dos direitos de segunda dimensão, estando fortemente cravado no constitucionalismo social, como ponto de encontro dos anseios sociais relativos à concretização de uma existência digna. Todavia, é também, o direito do trabalho, o que mais sofre em momentos como os atuais, em que os ventos da racionalidade economicista e individualista se sobrepõem. Foi em razão de momentos de resistência - como este - que, historicamente, a preocupação com a dignidade do trabalhador levou, em 1919, auge da exploração econômica do trabalho, à criação Organização Internacional do Trabalho (OIT) como instituição à qual se atribuiu a função de harmonizar, no nível internacional, as condições laborais. 
No Brasil, a atuação e o papel do direito do trabalho não têm sido diferentes. Antes da legislação trabalhista consolidada durante o período varguista, os trabalhadores e empregadores viviam num vácuo legislativo, no qual sempre prevalecia a autonomia da vontade do mais forte (empregador) - e é, infelizmente, a esse ponto que a nossa legislação retorna, com a Reforma Trabalhista. Na sua gênese, o direito do trabalho surgiu como uma via de inclusão socioeconômica dos pobres no universo da cidadania, a partir de um ideal de justiça social, o que vem sendo simplesmente ignorado pelo legislador pátrio contemporâneo.

Com o surgimento das principais leis trabalhistas na década de 1930 e 1940, que acabaram por culminar com a Consolidação das Leis do Trabalho (CLT), se manteve a proposta social de proteção social do trabalhador, inclusive com a promulgação de diversas outras leis esparsas. O que mais chama a atenção, a Reforma Trabalhista, é o retorno o retorno fortalecido da autonomia da vontade nas relações empregatícias e a possibilidade de se firmarem acordos entre empregado e empregador que se sobrepõem à legislação laboral (em consonância com a nova redação do art. 8o, §3o e do art. 611-A, da CLT, dado pela Lei 13.467, de 2017).

Na sua gênese, o direito do trabalho, inclusive no Brasil, teve no princípio da proteção ao trabalhador o parâmetro de realização e de adequação afirmativa da posição de hipossuficiência dos cidadãos (trabalhadores). Muito embora ficasse claro que o direito regular do trabalho não tinha a intenção de romper com o sistema capitalista, mas apenas de estabelecer parâmetros mínimos para a contratação do trabalho humano remunerado, evitando-se que o homem fosse considerado coisa. Ocorre que no momento atual tende-se a promover, sob o manto da "modernização", o retorno às condições de trabalho superadas pelas lutas históricas dos trabalhadores.

A teoria geral do direito do trabalho é assentada em princípios específicos que vão além da mera edição de normas que expressam regras acerca da contratação de mão-de-obra ou da jornada de trabalho. Para além disso, o direito do trabalho, impõe, a partir do reconhecimento do valor social do trabalho, os limites éticos ao capitalismo.

Nesta senda, o direito do trabalho surge, no contexto da hegemonia do liberalismo econômico, como alvo preferido e mais fácil aos ataques do capital. Ante as resistências dos setores empresariais, o direito do trabalho expressa o seu objetivo de regulamentar a compra e venda da força de trabalho, inserido nos sentidos originalmente apreendidos pelo trabalho (de cunho eminentemente capitalista, expresso na mera realização de atividade remunerada). É imperioso que se revitalize a acepção protetiva do direito do trabalho, fundada no valor social do trabalho, que vislumbra a promoção da dignidade dos sujeitos.

O direito do trabalho esquecido de suas bases históricas de luta, acaba por realinhar-se ao sentido meramente econômico do mercado, afastando-se da compreensão da dignidade do homem e, 
principalmente, da dignificação humana pelo trabalho. Não que, apesar da reforma, o direito do trabalho deixe de compreender a acepção capitalista formal de previsão de direitos, cujo objetivo é a regulação social que, muitas vezes, impede que as transformações sociais essenciais ao desenvolvimento ocorram. Ao contrário, o caráter conservador permanece, independentemente disto. A questão, é que nunca se viu retrocesso tão flagrante.

Numa acepção mais crítica, Ramos Filho (2012, p. 91), pondera que o "Direito Capitalista do Trabalho" ao contrário do que se apregoa, não protege o polo mais fraco da relação de trabalho, mas se constitui em:

[...] um ramo específico da ordem jurídica garantidora da propriedade dos meios de produção e das condições de sua reprodução, legalizando a exploração do trabalho humano. [...] legalizando o direito dos empregadores a subordinar os empregados mediante algumas contrapartidas, permite a racionalização econômica e a fixação das regras do jogo.

Muito embora se reconheça o caráter conservador e econômico do direito do trabalho, não se pode olvidar que sua concepção histórica, construída a partir da luta de classes e da resistência dos trabalhadores, é afeta aos direitos humanos do trabalhador.

Enquanto direito humano, o direito do trabalho não conserva a mesma concepção da época que serviu de inspiração às lutas de classes que originaram toda a gama de direitos relacionados à regulamentação do trabalho. É nesse sentido o entendimento de Castelo (2007, p. 90), para quem os direitos trabalhistas são condição do exercício da própria cidadania, ou seja, são condição essencial para a existência do próprio Estado Democrático de Direito.

As lutas dos trabalhadores se colocam como o contraponto social que estabelece o confronto com as demandas do capital. Esse confronto social, reconhecido pelas leis trabalhistas, e pelo próprio texto constitucional, quando admitem os direitos sociais como núcleo da atuação estatal, faz com que surjam e sejam implementadas políticas públicas sociais que são o instrumento para a materialização dos direitos sociais e que devem servir de resistência/impedimento normativo para os retrocessos.

Como se pode vislumbrar, os direitos laborais envolvem lutas por espaços de poder e embates de interesses, que exigem ações efetivas dos sujeitos sociais, de modo que a cidadania solidária, que gera a emancipação apenas é possível com a ampliação da ideia de cidadania, que passa, necessariamente, pelas lutas dos trabalhadores (ARAÚJO, 2017).

Com a consolidação do Estado Democrático de Direito amplia-se o reconhecimento dos direitos sociais, contudo o ideário capitalista é incompatível com ideia de igualdade afirmada pelos direitos de segunda dimensão assentados nos direitos do trabalho. Essa incoerência valorativa gera um déficit real 
na realização dos direitos laborais, eminentemente em países em desenvolvimento como o Brasil, que passam atualmente por uma das piores crises (econômica, social e política) de sua história. É por essa, dentre outras razões, que o direito do trabalho passa hoje por um processo de deslegitimação que implica o "declínio do poder unificador e legitimador dos grandes relatos da especulação e da emancipação (LYOTARD, 1998, p. 69)".

A crise do capital se aprofunda e as questões acerca da permanência da centralidade do trabalho na sociedade globalizada atual vêm à tona. As funções definidas para o direito do trabalho, como paradigma da proteção social, são objeto de reflexão ante o contexto de crise social que afasta milhões de pessoas da participação social - gerando desigualdades e aprofundando a pobreza e a marginalização. Como bem pontua Cecato (2006, p. 62),

[...] com as mudanças introduzidas pela intensificação da globalização econômica em todas as modalidades de relações sociais, fogem do alcance das negociações os princípios e garantias já assentados ao longo do século XX e, com estes, quaisquer exigências relativas à melhoria das condições de trabalho. $O$ primado do trabalho edificado junto ao Estado de Bem-estar-social padece da mesma agonia.

Os efeitos da globalização econômica são agravados no Estado brasileiro (assim como em outros com perfil semelhante), em decorrência das condições de subdesenvolvimento. Em razão destas, o Brasil não chegou a construir um Estado de Bem-Estar Social, pautado na cidadania. Em outros termos, não obstante tenha estabelecido a construção de uma sociedade solidária como objetivo, o Brasil não foi capaz de legitimar esse fundamento constitucional de sociedade solidária, da mesma forma que, embora tenha implementado ações com o propósito de compensar situações de injustiça histórica de discriminações sofridas por determinados grupos ou minorias em razão de sexo, raça, crença ou situação econômica, não tem permitido que esses sujeitos sociais participem integralmente do processo de desenvolvimento.

A luta pela superação da crise do Estado Democrático de Direito passa pela necessidade de reconhecimento e efetivação das políticas sociais e pela exigibilidade dos direitos sociais fundamentais num ambiente de globalização, de modo a centralizar esforços no valor social do trabalho. Antunes (2007a, p. 88) aduz ainda que a superação da crise do trabalho apenas seria possível com o trânsito da sociedade do trabalho abstrato para a uma sociedade emancipada, fundada no trabalho concreto que pressuponha uma redução da jornada de trabalho e a ampliação do tempo livre, ao mesmo tempo em que se assente na transformação radical do trabalho estranhado em um trabalho social.

Nessa visão, o trabalho apresenta-se como fonte e base para a emancipação de consciência 
omnilateral, na qual o homem passa a se sentir completo a partir de sua convivência em sociedade e através do trabalho. Ausente o valor social do trabalho, o trabalho deixa de ter o sentido de realização do homem e passa a figurar apenas como elemento de alienação, que priva e exclui o homem da participação cidadã no seu próprio destino, desumanizando o trabalho e ligando-o a precarização que fere a justiça social.

A superação da crise do capital, que atinge diretamente o trabalho requer ações que condicionem o reconhecimento do papel central do trabalho, da "[...] classe-que-vive-do-trabalho como sujeito potencialmente capaz, objetiva e subjetivamente, de caminhar para além do capital (ANTUNES, 2007a, p. 88)". A crise do Estado, a qual expõe a classe trabalhadora aos inúmeros problemas decorrentes da reestruturação produtiva e da acumulação flexível, tem provocado, dentre outros problemas,

[...] o desemprego estrutural, um crescente contingente de trabalhadores em condições precarizadas, além de uma degradação que se amplia, na relação metabólica entre homem e natureza, conduzida pela lógica societal voltada prioritariamente para a produção de mercadorias e para a valorização do capital (ANTUNES, 2007, p. 15).

É evidente que a perspectiva acerca do direito do trabalho continuará sempre em transformação, erigindo à época atual uma nova compreensão que exige uma revitalização da compreensão do direito ao trabalho enquanto elo essencial aos direitos humanos. Os direitos sociais, principalmente, têm o condão de tornar possível a luta pela sedimentação da ideia de cidadania solidária que possibilite aos seres humanos acesso ao desenvolvimento.

Os direitos trabalhistas se traduzem numa regulação social, com vistas à emancipação, pautados numa ética política e social que é ajustada aos novos tempos, em que a igualdade e a distribuição são consideradas elementos essenciais para a sociedade fundada no trabalho e cujo objetivo primordial é a emancipação social de todos.

3 Direito ao trabalho e promoção da cidadania: a acepção de acesso do valor social do trabalho como instrumento de valorização do trabalhador

A Constituição Federal da República Federativa do Brasil de 5 de outubro de 1988 elenca em seu artigo 60 os seguintes direitos sociais: à educação, à saúde, à alimentação, ao trabalho, à moradia, à lazer, à segurança, à previdência social, à proteção à maternidade e à infância e à assistência aos desamparados.

Todos esses direitos têm entre si um fundamento comum, o trabalho. São direitos 
correlacionados, interdependentes e dependentes do trabalho. É o trabalho que gera os recursos para que o cidadão possa materializar o alicerce para o desenvolvimento e a proteção desses direitos sociais constitucionalmente assegurados.

A própria Constituição, em seu artigo 70 apresenta um rol de direitos assegurados especificamente aos trabalhadores, os quais não excluem outros direitos que visem à melhoria da sua condição social ${ }^{5}$. As regras do direito do trabalho acabam por submeter à atuação econômica à congruência constitucional expressa pelos direitos do rol do 7ํㅜ, servindo, em tese, como balizas claras para a conformação social da economia.

Assim, são esses direitos, assegurados no artigo 7ํㅡ, verdadeira face do direito do trabalho na Constituição Federal de 1988, inegavelmente, conformadas aos princípios do valor social do trabalho e da valorização do trabalho humano, os quais se conjugam e servem de contraponto ao princípio da liberdade de iniciativa, também de expressão constitucional.

É necessário que se mencione nesse ponto que o direito do trabalho, ramo autônomo do direito, é complementar ao direito ao trabalho - embora dele se diferencie - por ser a feição normativa do valor social do trabalho que garante direitos mínimos aos trabalhadores como remuneração justa e equitativa entre homens e mulheres, condições de trabalho seguras e higiênicas, lazer, jornada de trabalho razoável, descanso e férias remuneradas, além do direito de associar-se e de filiar-se a sindicatos, de realizar greves, e de ter assegurada a previdência.

Quanto ao direito ao trabalho a sua compreensão como direito refere-se à expectativa legítima de o cidadão ter acesso a uma atividade que lhe garanta o sustento e que lhe assegure as condições mínimas de proteção e cidadania, através da oportunidade de ocupar um posto de trabalho (não exclusivamente de emprego), capaz de possibilitar a dignidade consentânea a sua realização pessoal. 0 direito ao trabalho é o oposto ao desemprego ou à desocupação.

Sob esse prisma, o direito ao trabalho poderia ser encarado numa dupla visão instrumental e substantiva. Na visão instrumental o direito ao trabalho seria responsável pela articulação dos meios para se atingir os objetivos relativos à promoção do acesso ao trabalho, promovendo a superação da crise do emprego, através de políticas públicas de incentivo à contratação, com investimentos sociais em setores da econômica ligados à produção industrial, agrícola e à capacitação dos trabalhadores.

Na visão substantiva, o direito ao trabalho se revelaria como a própria promoção, acesso e manutenção do trabalho, constituindo-se como objetivo a ser alcançado (nessa medida se tornando

\footnotetext{
${ }^{5}$ Há que se salientar, que os direitos previstos no artigo 7ํㅡ, são os únicos assegurados contra a desregulamentação promovida pela Reforma Trabalhista (art. 611-B, CLT, acrescido pela reforma), são, portanto, as únicas normas que se mantém incólume aos avanços precarizantes neoliberais - são a barricada da resistência do direito do trabalho em tempos de ataques à cidadania social.
} 
mais programático), factível através de uma política contínua de desenvolvimento e valorização da cidadania.

O que se deve ter em mente é que ambas as visões devem atuar em conjunto. $O$ direito ao trabalho deve ser capaz de estruturar políticas públicas de caráter social que possibilitem a realização de outros direitos sociais e econômicos (como o próprio direito do trabalho) que demandam realização por parte do Estado.

A própria Constituição Federal, no seu artigo 7o, incisos I e XXVII, prevê os reflexos constitucionais do direito ao trabalho, estabelecendo respetivamente a "relação de emprego protegida contra despedida arbitrária ou sem justa causa, nos termos de lei complementar, que preverá indenização compensatória, dentre outros direitos" e a "proteção em face da automação, nos termos da lei".

No caso do inciso I, a eficácia contida determinada pela exigência de lei complementar foi suprida pelo artigo 10 do Ato das Disposições Constitucionais Transitórias (ADCT), que fixa a indenização compensatória à dispensa sem justa causa, a 40 por cento do valor do depósito de Fundo de Garantia por Tempo de Serviço (FGTS) ${ }^{6}$.

Na hipótese do inciso XXVII, a previsão constitucional da regulamentação da proteção contra a automação ainda permanece sem regulamentação, portanto, inviabilizando o exercício da garantia constitucional. Clara situação de inconstitucionalidade por omissão. A ausência de regulamentação viola e impede que medidas efetivas de proteção em face da automação sejam efetivadas, o que revela uma crise de normatividade do direito ao trabalho.

Ainda quanto à crise regulatória do direito ao trabalho, a denúncia da Convenção no 158 da OIT, demonstra a inviabilidade de realização plena do direito ao trabalho no Brasil. A proteção do trabalhador contra o término abrupto da relação laboral, sem a garantia de defesa do trabalhador impede e viola a dignidade e revela a dificuldade dos juristas brasileiros de compreender e garantir a máxima efetividade ao direito ao trabalho.

É evidente que ausência de regulamentação desses direitos não é simplesmente uma opção legislativa, o que se enfrenta é a materialização da crise de legitimidade no exercício dos direitos sociais. Vale salientar que, para que o direito ao trabalho seja exercido em sua plenitude, o Estado deve assegurar todas as proteções previstas ao trabalhador, definidas e regulamentadas pelo direito do trabalho, o que afirmará a prevalência do trabalho decente como corolário da dignidade humana do trabalhador.

\footnotetext{
${ }^{6}$ Embora, também nessa seara, a nova regulamentação cria a situação da "dispensa consensual", que reduz à metade o valor da indenização sobre o saldo do FGTS, relativizando também essa regra de proteção da relação de emprego (art. 484-A, CLT).
}

Revista de Direito da Cidade, vol. 11, no 2. ISSN 2317-7721 pp. 783-807 
Há que se deixar claro ainda que, no contexto hodierno, não basta fundar, proclamar ou proteger o direito ao trabalho, como elemento de emancipação, como bem lembra Bobbio (2000, p. 505), o problema da realização dos direitos não é jurídico, moral nem filosófico, mas de cunho prático.

Para que seja exercido em sua plenitude, o direito ao trabalho deve ser efetivado sob os auspícios do direito ao desenvolvimento, que tal como afirmado por Feitosa (2013, p, 112), deve:

[...] respeitar e incorporar os ditames culturais locais e regionais, padrões ambientais transacionais, solidariedade intergeracional, entre outros princípios com base na ampliação da participação popular. [...] o direito ao desenvolvimento radica mais confortavelmente na relação entre os direitos sociais e culturais, unindo, pelos extremos, o individual/grupal e o global, ao respeitar os direitos sociais e culturais de coletividades atingidas pelos impactos negativos das externalidades econômicas, quando pugna pela proteção ambiental em benefícios da espécie humana ou quando atua na luta pela inclusão social dos povos do planeta. Pode ser encontrado no direito ao trabalho, à saúde, à paz internacional, à autodeterminação dos povos, ao meio ambiente sadio e efetivamente equilibrado, estando permeado em todos esses eixos, pela expressão livre e democrática de sujeitos e coletividades (FEITOSA, 2013, p. 111$112-$ Grifo nosso).

Dessa feita, resta clara a ligação entre o direito ao desenvolvimento e o direito ao trabalho. 0 principal requisito, pois, para que o direito ao trabalho seja efetivado é a existência do próprio trabalhoocupação. Assim, não se fala aqui, do emprego no sentido estrito, ou seja, do vínculo de emprego nos moldes da CLT, mas em toda atividade que gera renda e promove o acesso dos cidadãos aos bens essenciais a sua existência com dignidade.

A dignidade do trabalhador, assim como sua cidadania, não se aparta de sua principal atividade: prendem-se, ambas, portanto, à sua condição laboral, não apenas em razão da garantia de subsistência material, mas também pela persistência da relação com a sociedade e pelo respeito atribuído a quem trabalha, uma vez que o trabalho é um dos maiores valores sociais.

Ainda que diversos ordenamentos ocidentais tenham encontrado alternativas para suprir as necessidades materiais do trabalhador desempregado, tais soluções não chegam a substituir o emprego. Como bem aponta Cecato (2008, p. 178):

[...] inalienável é, antes de tudo, o direito de trabalhar e, portanto, o acesso ao trabalho, sem o qual, evidentemente, não há que se falar em participação ativa do trabalhador na produção. [...] o trabalho realizado em condições de dignidade é meio de provimento de necessidades materiais, morais e emocionais do trabalhador, aí incluídas a autoestima e a inserção deste na comunidade em que vive. Para além disso, o trabalho é capaz de minorar a vulnerabilidade do trabalhador à violência e à exploração de toda sorte. Igualmente inalienável é o direito do trabalhador a si beneficiar dos resultados de todo o processo produtivo, 
o que supõe auferir remuneração que permita o acesso ao consumo (CECATO, 2008, p. 178).

Como se percebe, a feição clara da decência do trabalho é elemento intrínseco à realização do valor social do trabalho. Contudo, essa feição apenas é possível de ser posta em prática se houver postos de trabalho disponíveis para aqueles que têm condições de trabalhar, e que, obviamente, as regras do direito do trabalho sejam cumpridas garantindo a qualidade dessas ocupações e a dignidade dos trabalhadores.

Nesse horizonte, o princípio da busca pelo pleno emprego deve orientar (como norma objetivo) e conformar as ações do Estado em prol da realização do direito ao trabalho. Nesse sentido, Grau (2005, p. 253) expressa:

[...] consubstancia também, o princípio da busca do pleno emprego, indiretamente, uma garantia do trabalhador, na medida em que está coligado ao princípio da valorização do trabalho humano e reflete efeitos em relação ao direito social ao trabalho (artigo 6a, caput)

A elevação dos patamares produtivos, numa estrutura solidária e cujo planejamento seja voltado para o desenvolvimento deve ter a ampliação dos fatores e recursos produtivos como meta de promoção do trabalho. A orientação do princípio da busca do pleno emprego, em prol do direito ao trabalho determina que as políticas econômicas não promovam recessão econômica capazes de restringir ou impedir o acesso dos cidadãos ao mercado de trabalho.

O princípio da busca do pleno emprego deve servir de parâmetro para a realização de políticas públicas anticíclicas que impeçam as consequências mais drásticas da crise econômica nos índices de empregabilidade, exigindo que o direito ao trabalho seja posto em prática como um elemento de dignificação do homem e de promoção de emancipação. Isto quer dizer que apenas o trabalho é capaz de garantir de modo integral a dignidade e os pressupostos e dimensões do desenvolvimento humano.

$\mathrm{O}$ trabalho apresenta-se, dentre outras maneiras, como a forma universal de acesso à renda, garantindo inserção econômica ao trabalhador. Inclusive, é condição para o exercício do direito ao trabalho que o cidadão tenha a retribuição salarial condizente com a atividade desenvolvida e que essa renda seja capaz de satisfazer suas necessidades mínimas, bem como de sua família. Entretanto, não apenas a abordagem relativa à realização de suas necessidades básicas é importante.

Tem importância equivalente a prevalência da justiça social como corolário do "desenvolvimento como liberdade" proposto por Sen (2005), o qual leva em consideração os aspectos 
jurídicos, as perspectivas políticas e, em especial, as implicações sociais do acesso ao trabalho. A inclusão laboral favorece a estruturação do homem enquanto sujeito social já que se estabelece como a maior e mais importante forma de sustento e de interação social do homem. O trabalho se revela como instrumento de autoafirmação e de auto-identificação do homem como sujeito social.

Ao ter acesso ao trabalho o homem deixa de ser encarado como mero indivíduo biológico que interage com a natureza, tornando-se capaz de superar essas barreiras naturais. Na mesma linha, Delgado (2007a, p. 29) sustenta que o trabalho, em especial o trabalho regulado, por assegurar um patamar mínimo de direitos ao indivíduo, apresenta-se como importante instrumento de afirmação socioeconômica de grande parte da sociedade, sendo, portanto, decisivo para a estabilidade da democracia.

No aspecto do acesso ao trabalho, supõe-se que o direito ao trabalho seja escolhido ou livremente aceito, eliminando do seu sentido qualquer espécie de escravidão, servidão ou trabalho forçado (pilar inequívoco do trabalho decente, nos termos propostos pela OIT). Decorre ainda do acesso ao trabalho, a necessidade de que seja disponibilizada para o seu exercício pleno, a formação técnicoprofissional ou a qualificação para o desempenho da atividade laboral.

No outro aspecto, o direito ao trabalho aponta para as qualidades e a natureza da atividade desempenhada, que devem assegurar ao trabalhador condições dignas e satisfatórias para a vida. Garante-se, então, com o reconhecimento do direito ao trabalho como consectário da própria liberdade do trabalho, outras garantias inerentes ao direito do trabalho, tais como a associação voluntária, a igualdade das relações entre patrão e empregado, o ensino gratuito, a educação profissional, a instituição e o estabelecimento, pelo Estado de obras e políticas públicas destinadas a capacitar, qualificar e promover a absorção dos trabalhadores pelo mercado.

O direito ao trabalho decorre, assim, de uma nova categoria de direitos positivados que exigem a prestação estatal para que se possa alcançar o pleno desenvolvimento da existência individual. O Estado como sujeito passivo do direito ao trabalho deve promover, definir e executar políticas públicas econômicas, de trabalho, habitação, saúde, saneamento básico etc. no intuito de garantir a inserção do sujeito na economia. Através da atuação Estatal, a liberdade de agir dos sujeitos mais vulneráveis socioeconomicamente deixa de ser uma mera previsão legal e se torna um instrumento de poder.

Há que se afirmar ainda que o direito ao trabalho, decorre também dos artigos 6 e 7 do Pacto Internacional dos Direitos Econômicos, Sociais e Culturais (PIDESC) e do artigo 8 do Pacto Internacional dos Direitos Civis e Políticos (PIDCP), além das convenções 29 e 105 da OIT, as quais afirmam claramente a perspectiva do acesso ao trabalho, como feição dos direitos humanos.

É evidente, contudo, que o direito ao trabalho não descura de outra perspectiva, qual seja o direito a que esse trabalho seja desempenhado de tal modo que assegure as condições mínimas e 
satisfatórias de vida com dignidade (o que fortalece de modo ainda mais evidente o seu caráter de direito humano). Menos do que estabelecer novo direito, importa criar, a partir do direito ao trabalho, estruturas que tendam a conferir maior efetividade aos direitos laborais já existentes. É por essa razão que se pode compreender o direito ao trabalho como um direito-plataforma ${ }^{7}$, sem o qual um rol extenso de outros direitos não poderia ser exercido.

Quando, por exemplo, se exclui parcela da população da iniciativa e criatividade socioeconômica em razão de problemas de inserção, os quais marginalizam os pobres, significa que o potencial de trabalho produtivo e criativo dessas pessoas encontra-se, utilizando-se a expressão de Jacobs (2001), "automaticamente esterilizado". Não seria possível a esses sujeitos "sem trabalho" utilizar-se dos mecanismos sociais, e, portanto, serem inseridos, na base do desenvolvimento do qual deveriam ser usufrutuários.

Essa exclusão social gera e reforça a ideia de fraqueza do processo de crescimento econômico capitalista que desconhece, na prática, a imperiosidade de gerar cada vez mais as potencialidades de participação humana num processo sustentável de desenvolvimento com a perspectiva de realização de oportunidades sociais.

Combater a ausência de trabalho, para parcela pobre, no mercado, por falta de oportunidade de acesso à educação e à capacitação profissional, é a chave para novas alternativas de melhoria de vida e de acesso aos bens sociais para a satisfação de necessidades que vão além da mera subsistência. Nesse contexto, o direito ao trabalho deve ser repensado de modo que a sua concepção normativa seja ampliada, isto porque, como aponta Marques:

Contemporaneamente, prevalece a interpretação de que o direito ao trabalho envolve o direito ao acesso e a manutenção de uma ocupação produtiva, o que confere uma dimensão promocional à atividade do Estado, mas não atribui aos indivíduos um instrumento judicial específico para assegurá-lo. Nos termos da compreensão prevalecente na atualidade na doutrina e jurisprudência trabalhista pátrias, embora o direito ao trabalho possa ser invocado, por exemplo, para coibir uma despedida em massa, ou uma despedida abusiva, ou para impedir práticas discriminatórias no acesso ao emprego, não há obrigação legal de que um particular ou o Estado ofereça um posto de trabalho a um determinado individuo apenas em razão do reconhecimento do direito ao trabalho (MARQUES, 2011, p. 98).

O direito ao trabalho deve ser entendido então como direito ao trabalho em condições decentes

\footnotetext{
${ }^{7}$ Para Feitosa (2013, p. 489), os direitos-plataforma são aqueles capazes de integrar o conjunto dos demais direitos humanos no objetivo principal de conferir organicidade ao sistema e garantir a promoção e a aplicação desses mesmos direitos. Eles reclamam uma estrutura favorável para a sua realização, que apenas é possível a partir do diálogo e do exercício de realização de outros direitos.
} 
de forma a assegurar a sua valorização social, assim como o efetivo respeito à dignidade humana do trabalhador. O direito ao trabalho deve ser a chave de inserção socioeconômica de todos, mas não a qualquer custo, como se depreende do discurso flexibilizatório-precarizante, que se utiliza do discurso da "empregabilidade" para reduzir direitos e garantias fundamentais do trabalhador.

O direito ao trabalho deve ser posto em prática consoante a materialidade constitucional, definida pelo valor social do trabalho, e nos termos da efetivação do princípio da busca pelo pleno emprego, com ações e políticas públicas de enfrentamento às crises e às retrações econômicas, sempre centradas na pessoa humana e na preocupação social.

À luz das reflexões travadas, o estabelecimento de uma necessária correlação entre o direito ao trabalho e o direito do trabalho, tem (e deve ter cada vez mais) como ponto de entroncamento o valor social do trabalho, como mote e superestrutura normativas de impedimento dos retrocessos jurídicos.

O direito ao trabalho implica, pois, necessariamente uma organização do trabalho que gere transformação. Consistindo no direito de todo homem viver do seu trabalho, e na contrapartida, de que a sociedade deva propiciar trabalho àqueles que se encontrem em condições físicas e psíquicas de trabalhar, mas que não conseguem em razão das condições econômicas ou da indisponibilidade dos meios produtivos.

Quanto ao direito ao trabalho, a sua perspectiva de efetivação é mais complexa, estabelecendo uma necessidade de interação vertical, a partir do Estado, com fulcro na solidariedade (ARAÚJO, 2018). Devem ser eliminados os obstáculos que impedem a ampliação dos postos de trabalho com a adoção de políticas econômicas inclusivas e com a adoção de uma ética que considere a centralidade do trabalho e do sujeito social. Nesse momento, o direito ao trabalho e o direito do trabalho se reencontram, uma vez que a promoção da decência e da dignidade do trabalho apenas é possível se se permitir o acesso ao trabalho com a garantia e o respeito às normas mínimas de proteção laboral.

O viés substantivo apresentado pelo questionamento acerca da pretensão do direito ao trabalho se revela pela necessidade de promoção e observância dos direitos humanos que devem ter como objetivo fundamental a concretização do desenvolvimento, a partir de instrumentos e ações que sejam capazes de promover a emancipação e a cidadania, mantendo postos de trabalho já existentes e criando novos postos, de modo a reduzir a cada vez maior massa de trabalhadores desempregados no Brasil.

4 Da pressuposição normativa de uma complementaridade entre o direito do trabalho e o direito ao trabalho 
A partir da compreensão acima referida acerca da coligação entre o direito do trabalho e o direito ao trabalho, pode-se afirmar que as acepções de proteção e acesso ao trabalho correspondem, respectivamente, aos fundamentos jurídicos abrangidos na construção normativo-constitucional do valor social do trabalho.

No intento de demarcar a linha que separa (ao menos academicamente) o direito do trabalho do direito ao trabalho, pode-se afirmar que o direito do trabalho tem como características a sua inserção no contexto dos direitos sociais de segunda dimensão, apresentado como um direito em favor do trabalhador (empregado, via de regra), exercido através do Estado, em uma acepção mais protetiva (ao se referenciar o conteúdo do valor social do trabalho).

Por sua vez, o direito ao trabalho situa-se no universo maior dos direitos humanos, caracterizado como um direito de todo e qualquer cidadão, ou de grupos de cidadãos, detendo, por sua vez uma acepção mais promocional, no contexto da agenda democrática do neoconstitucionalismo social, com prioridade na realização da dignidade pelo trabalho (seja no acesso ou na manutenção do posto de trabalho).

Pode-se, pois, referir que o direito ao trabalho tem um caráter mais holístico do que o direito do trabalho, tendo como titularidade todos os seres humanos, povos e coletividades humanas (e não apenas aqueles envolvidos na relação de trabalho, como é o caso do direito do trabalho) sendo centrado no ser humano, como detentor de dignidade.

O direito ao trabalho é encarado como parte integrante do direito ao desenvolvimento e, portanto, dos direitos humanos, considerados em sua matriz internacional ou global, com clara repercussão nas ordens internas, sendo alicerce de um direito de fraternidade, portanto, de terceira dimensão, que deve ser exercido através do Estado, em benefício de uma coletividade detentora do direito à dignidade.

O direito ao trabalho assenta-se na solidariedade como fundamento ético-normativo de realização, cujos atributos de realização "[...] se mesclam nas relações entre os três setores - Estado, mercado e sujeitos sociais - de modo mais equilibrado, embora não gerem efetivação imediata de direitos humanos, considerando-se que esses direitos demandam discussão e concreção em ambiente democrático e participativo (FEITOSA, 2013, p. 134)". Isto porque, muito além de promoção de acesso ao trabalho, essas relações advindas do exercício do direito ao trabalho devem estar pautadas no caráter protetivo do direito do trabalho.

O direito do trabalho é fundamentado na diversidade das relações trabalhistas que exigem proteção. Por sua vez, o direito ao trabalho reside nos padrões heterogêneos de cada cultura, de cada região, tendo como ponto primordial de realização, a focalização de ações que se pautam na transversalidade de medidas que promovam o trabalho em condições de dignidade e decência. 
Essa transversalidade pode ser expressa a partir da importante contribuição trazida pelo direito ao desenvolvimento. Consoante aponta Feitosa, em sua dimensão normativa, o direito ao desenvolvimento é capaz de:

[...] adicionar valores éticos e morais à prática do desenvolvimento, assim, os processos de desenvolvimento passaram a ser orientados pela observância dos princípios contidos nos instrumentos internacionais dos direitos humanos, em relação às metas (resultados) ou ao processo do desenvolvimento em si (FEITOSA, 2013, p.149).

Por essa razão, pode-se afirmar que os direitos humanos e o direito ao trabalho são estruturas normativas que se assemelham também por sua fluidez e capacidade de se transversalizarem, dependendo de efetivação pela atuação prática e também através da materialização na luta, no campo dos interesses em composição ou em confronto.

Em decorrência da acepção de realizabilidade do direito ao trabalho e de sua aproximação aos direitos humanos é que o valor social do trabalho pode ser encarado sob uma visão instrumental em que a realização dos direitos ("ao trabalho" e "do trabalho") se configura como meio para atingir os objetivos finais da República, expressos no objetivo maior do desenvolvimento. Nesse contexto, é imperioso que sejam estruturadas ações de planejamento acerca da promoção do trabalho, a partir da formulação de políticas públicas gerais para fins substantivos específicos.

A possibilidade de solução para a onda precarizante e que põe em xeque os direitos sociais é a revitalização do trabalho enquanto instrumento de reivindicações, inclusive com a ampliação do seu leque de proteção para outros grupos sociais, como a classe-que-tem-condições-de-viver-do-trabalho (ARAÚJO, 2017a).

Em face do movimento flexibilizatório e precarizante, os direitos laborais, como instrumentos de estabilização das conquistas sociais dos trabalhadores, devem apresentar-se rígidos, com o fito de manter a ordem e possibilitar a resistência ante o bombardeio do capital.

O valor social do trabalho deve possibilitar a transformação da realidade, com o intento de promover a implementação de garantias sociais mínimas aos mais vulneráveis, mas mantendo também a maleabilidade das regras do direito do trabalho, cuja aplicação deve servir para ampliar a eficácia de novas conquistas sociais. Nesse ponto, julga-se oportuno a remissão às reflexões de Ráo, para quem:

A solução para que o Direito do Trabalho tenha sua eficácia preservada está na própria ordem jurídica. O Direito instrumentaliza sua própria observância. Desse modo, assume a feição de força social propulsora, quando visa a proporcionar aos indivíduos e à sociedade o meio favorável para o aperfeiçoamento e progresso da humanidade (RÁO, 2004, p. 54-55).

Vale então a ponderação no sentido de que a inclusão da proteção do trabalho e do acesso ao 
trabalho, como acepções do valor social do trabalho, não significa apenas a sua correlação com perspectiva do ingresso no mercado de trabalho. Mais do que isso, o valor social do trabalho ao determinar em seu conteúdo um direito ao trabalho, estabelece que esse direito deva ser exercido a partir de uma racionalidade solidária e ética que tem como suporte o princípio da dignidade.

Mencionada compreensão não se dá de modo único nas regras de proteção do trabalho como horas extras, descanso remunerado, salário, direito de greve, dentre outros direitos de proteção do trabalhador. A compreensão ética e de dignidade do valor social do trabalho se expressa a partir da normatividade dos princípios, os quais exigem realização plena, irradiando os seus efeitos para os mais variados campos de proteção do ser humano.

O valor social do trabalho deve nortear a ideia de proteção social e de acesso ao trabalho para além das relações eminentemente trabalhistas, abrangendo também a realização de ações relacionadas, por exemplo, às políticas da assistência social. A essa evidência,

O passo inicial para a concretização desse objetivo é a releitura das normas de direitos fundamentais do trabalhador, lastreada na normatividade constitucional, compreendida como o acontecimento reflexivo da síntese entre o valor-trabalho, a imperatividade das normas justrabalhistas endereçadas à melhoria das condições sociais e a realidade do mundo do trabalho (ARAUJO, 2012, p. 132).

Nesta senda, é de se observar que a realocação dos direitos laborais como instrumento fomentador de justiça social depende da afirmação de sua centralidade e essencialidade para a realização da dignidade da pessoa humana, enquanto princípio geral amplo e presente em todos os campos do direito. Isto porque não é o fato de o cidadão ser efetivamente remunerado ou estar ligado a uma relação jurídica empregatícia que o tornará sujeito de uma relação pautada na dignidade decorrente dos direitos sociais.

As ações estatais oriundas do trabalho, que não devem ficar restritas ao conjunto de regras do direito do trabalho, devem ampliar o seu campo de abrangência de modo a tornar real a proteção social material prevista no texto constitucional de 1988, as quais têm como titulares, também, todos os cidadãos, inclusive os beneficiários das políticas sociais de assistência, aqueles que compõem a classeque-tem-condições-de-viver-do-trabalho.

Há de se observar então, quanto à natureza, que o valor social do trabalho, não seria um direito no sentido clássico. Poder-se-ia defini-lo como um meta-direito, princípios conformador e orientador, cujo conteúdo é o direito a ter políticas, sendo seu titular não um único indivíduo, mas toda a coletividade, a quem devem ser assegurados o direito ao trabalho e as normas de proteção do direito do trabalho. 
Conquanto não se possa deixar de enxergar as dificuldades para sua realização, o valor social do trabalho torna-se verdadeira cláusula geral que deve orientar não apenas ações imediatas das políticas governamentais, mas também a condução das ações estatais (e de toda a sociedade) no sentido de se atingir os fins prometidos pelas promessas constitucionais de solidariedade, promoção do desenvolvimento, erradicação da pobreza e promoção da igualdade material.

O valor social do trabalho - a partir da articulação de suas acepções de proteção e acesso ao trabalho, representadas pelo direito do trabalho e pelo direito ao trabalho - está assentado nas medidas que devem ser adotadas para alcançar os objetivos relativos às políticas laborais, as quais se tornariam realizáveis, a médio e longo prazos, consoante o princípio econômico da busca do pleno emprego (artigo 170, VIII, da Constituição Federal de 1988).

O valor social do trabalho é, portanto, consubstanciado numa ideia de decência do trabalho, a qual volta-se para a inserção econômica, para a redução da pobreza e das desigualdades, bem como para a promoção do desenvolvimento em condições de equidade. Obviamente para que haja a implementação de políticas públicas de promoção de trabalho, faz-se necessário um planejamento abrangente que harmonize todas as atividades estatais e os objetivos econômicos, voltados para uma preocupação social e humana. Impõe-se, a essa evidência, a superação da inefetividade estatal enquanto promotor do desenvolvimento centrado na pessoa humana e na promoção do acesso ao trabalho.

As políticas públicas fundadas no direito ao trabalho devem ter como escopo a ampliação da cidadania, através da integração igualitária da população na sociedade (superando o bloqueio dos interesses particulares, os quais impedem o acesso ao trabalho), em face do princípio da máxima eficiência e estruturadas na efetivação dos objetivos constitucionais, insculpidos na Carta de 1988.

Dentre esses fins, coloca-se o objetivo maior de romper a estagnação provocada pela rigidez estrutural decorrente de séculos de excessiva concentração de rendas e de dominação e exploração pelo capital, que tem se prolongado ao longo dos séculos. Além da própria estrutura social tradicionalmente constituída pela patrimonialidade e pela racionalidade econômica, é preciso que sejam enfrentadas as dificuldades sociais, econômicas e, principalmente, políticas que atentam, hodiernamente, contra os direitos trabalhistas assegurados na legislação brasileira.

No sentido da responsabilidade acerca da efetivação. O direito do trabalho tem como fundamento de concretização o dever de cooperação social, uma vez que os tomadores de serviço (empregadores) devem respeitar e promover a efetividade das normas que regulamentam o contrato de trabalho, nas relações entre particulares - revelando o aspecto de sua eficácia horizontal.

A reforma trabalhista como medida saneadora da crise, na realidade aponta na direção da redução de direitos, como mecanismo para solucionar uma crise do capital especulativo e financeiro. 
Ao contrário do que seria mais lógico ocorrer, no sentido de ampliação da produção e da valorização do trabalho humano, a reforma contraria a lógica social e a racionalidade solidária, em benefício do mercado e da ideologia neoliberal e precarizante.

Na realidade, a grande virada para que a atuação coligada dos dois direitos ("ao trabalho" e "do trabalho") seja frutífera é a necessidade de se alcançar ou manter resultados econômicos, de modo que seja possível a realização dos direitos humanos, a partir de uma necessidade real da sociedade, fundada na inserção laboral que enseja emancipação e que esteja realmente preocupada com a pessoa humana.

Assim, devem ser adotadas, "[...] agendas de planejamento econômico com base na industrialização geradora de empregos e na necessidade de programação estatal do desenvolvimento, entendido como processo plural, de natureza econômica, política e social (FEITOSA, 2013, p. 118)". As políticas públicas estatais, internacionais e supranacionais devem ser implementadas no sentido de promover a facticidade dos direitos sociais, a partir da realização, em especial do direito ao trabalho e do seu consectário e instrumento de proteção, o direito do trabalho, funcionando como mecanismos para solução da crise econômica e para a geração de novos postos de trabalho.

\section{Considerações conclusivas}

$\mathrm{Na}$ constante luta contra a exclusão social (pela integração social), é forçoso reconhecer que apenas políticas públicas estatais, adotadas a partir da ideia de valorização do trabalho, serão capazes de promover o desenvolvimento desse amplo espectro de atores sociais pobres, excluídos, marginalizados e sem acesso ao trabalho.

Especialmente após a edição da Reforma Trabalhista", a Lei no. 13.467 de 2017, várias conquistas sociais dos trabalhadores foram objeto de modificação ou "flexibilização". Todavia, embora pareça contraditório, ainda é possível reconhecer que o Brasil é um Estado que pode determinar, a partir do texto constitucional, um projeto de formação nacional que promova o desenvolvimento de forma igualitária, especialmente pela conformação à materialidade axiológica constitucional, cujo núcleo é de uma clara vertente social, voltada para a proteção e promoção do trabalho.

Não se pode olvidar que para a superação de uma crise que se arrasta desde meados de 2014, os meios mais eficazes para superação da crise de emprego são políticas públicas de trabalho. Os efeitos da globalização econômica são agravados no Estado brasileiro (assim como em outros com perfil 
semelhante), em decorrência das condições de subdesenvolvimento. Em razão destas, o Brasil não chegou a construir um Estado de Bem-Estar Social, pautado na cidadania.

Em outros termos, não obstante tenha estabelecido a construção de uma sociedade solidária como objetivo, o Brasil não foi capaz de legitimar esse fundamento constitucional de sociedade solidária, da mesma forma que, embora tenha implementado ações com o propósito de compensar situações de injustiça histórica de discriminações sofridas por determinados grupos ou minorias em razão de sexo, raça, crença ou situação econômica, não tem permitido que esses sujeitos sociais participem integralmente do processo de desenvolvimento.

A luta pela superação da crise do Estado Democrático de Direito passa pela necessidade de reconhecimento e efetivação das políticas sociais e pela exigibilidade dos direitos sociais fundamentais num ambiente de globalização de modo a centralizar esforços no valor social do trabalho.

Estaria então, o direito ao trabalho articulado com o direito ao desenvolvimento, no sentido de definir prioridades e ações que devam ser realizadas, sempre no intuito de promover as capacidades do indivíduo gerando ampliação de potencialidades econômicas, sociais, políticas e civis. Isto num contexto extremamente complexo e globalizado, enfrentando os mecanismos precarizantes e flexibilizatórios intentados pelo capital, assentados em políticas públicas de cunho social e, às vezes assistência, quase sempre de repercussão econômica, cuja instrumentalidade apenas seria possível através dos instrumentos protetivos garantidos pelo direito do trabalho.

Propõe-se assim, que os direitos decorrentes do valor social do trabalho não devem resvalar em um conteúdo meramente retórico, devendo ser exercitados no dia a dia, em demandas concretas, materializando as lutas sociais, sob pena de se realizar o triste prognóstico de Douzinas (2009) acerca do fim dos direitos humanos (e é evidente que ambas as acepções definidas e defendidas para o valor social do trabalho - proteção social e acesso ao trabalho - são, como se afirmou, faces dos direitos humanos).

\section{Referências}

ANTUNES, Ricardo. Os sentidos do trabalho: ensaio sobre a afirmação e a negação do trabalho. 9 reimp. São ANTUNES, Ricardo. Os sentidos do trabalho: ensaio sobre a afirmação e a negação do trabalho. 9 reimp. São Paulo: Boitempo, 2007.

ANTUNES, Ricardo. Adeus ao trabalho? ensaio sobre as metamorfoses e a centralidade do mundo do trabalho. 12. ed. São Paulo: Cortez; Campinas: Universidade Estadual de Campinas, 2007. 
ARAÚJO, Eduardo Marques Vieira. Trabalho, constituição e direitos fundamentais: uma releitura do princípio da valorização do trabalho. De Jure - Revista Jurídica do Ministério Público do Estado de Minas Gerais. v. 11, n.19, Belo Horizonte: Ministério Público do Estado de Minas Gerais - Centro de Estudos e Aperfeiçoamento Funcional, jul./dez. 2012, p. 112-135.

ARAÚJO, Jailton Macena de. Valor social do trabalho na Constituição Federal de 1988: instrumento de promoção de cidadania e de resistência à precarização. Revista de Direito Brasileira, v. 16, n. 7, p. 115134, São Paulo, Jan./Abr. 2017

ARAÚJO, Jailton Macena de. Cidadania, desenvolvimento e dignidade humana: uma releitura da esfera pública arendtiana à luz da solidariedade. Pensar, Fortaleza, v. 22, n. 2, p. 567-580, maio/ago. 2017. ARAÚJO, Jailton Macena de. Constituição, cidadania e trabalho: premissas para o reconhecimento de uma racionalidade estatal pautada na solidariedade. Direito, Estado e Sociedade, n.52 p. 134 a 158, jan/jun, 2018.

BOBBIO, Noberto. Teoria geral da política: a filosofia política e a lição dos clássicos. Trad. Daniela Beccaccia Versiani. Rio de Janeiro: Elsevier, 2000.

CASTELO, Jorge Pinheiro. A norma do direito do trabalho. Os fundamentos do direito do trabalho. In: CORREIA, Marcus Orione Gonçalves (org.). Curso de Direito do Trabalho. 1. vol. Teoria Geral do Direito do Trabalho. São Paulo: LTr, 2007, p. 85-98.

CECATO, Maria Áurea Baroni. A relativa relevância da Declaração de 1998 da OIT para a definição dos direitos humanos do trabalhador.Prim@Facie.vol. 5. n. 8. p. 62-74, João Pessoa: UFPB, 2006.

CECATO, Maria Áurea Baroni. Direitos laborais e desenvolvimento: interconexões. Boletim de ciências económicas, LI, pp. 173-191, Lisboa: Coimbra, 2008.

DELGADO, Mauricio Godinho. Direito do trabalho e inclusão social: o desafio brasileiro. Revista LTR. São Paulo, a. 70, n. 10, p. 1.159-1.169, out./2006.

DELGADO, Mauricio Godinho. Capitalismo, trabalho e emprego: entre o paradigma da destruição e os caminhos de reconstrução. São Paulo: LTr, 2007a.

DOUZINAS, Costas. O fim dos direitos humanos. Tradução Luzia Araújo. São Leopoldo: Unisinos, 2009.

FEITOSA, Maria Luiza Alencar Mayer. Direito econômico do desenvolvimento e direito humano ao desenvolvimento: limites e confrontações. In: FEITOSA, M. L. A. M. et al. (Orgs.). Direitos humanos de solidariedade: avanços e impasses, Curitiba: Appris, 2013.

GRAU, Eros Roberto. A ordem econômica na Constituição de 1988. 10 ed. rev. atual. São Paulo: Malheiros, 2005.

JACOBS, Jane. A natureza das economias. Trad. Paulo Anthero Soares Barbosa. São Paulo: Beca Produções Culturais, 2001. 
LA TOUPIE. Droit du travail. Dictionaire de politique. Disponível em: <www.toupie.org >. Acesso em 11 maio. 2015.

LYOTARD, Jean-François. A condição pós-moderna. Trad Ricardo Corrêa Barbosa. Rio de Janeiro: José Olympio, 1998.

MARQUES, Maria Celeste Simões. Controle e trabalho: exclusão e criminalização. In: DORNELES, João Ricardo Wanderley et al (org.). Estado, política e direito:políticas públicas e direitos fundamentais, vol. 2, Criciúma: UNESC, 2011, p. 95-105.

RAMOS FILHO, Wilson. Direito capitalista do trabalho: história, mitos e perspectivas. São Paulo: LTr, 2012.

RÁO, Vicente. O direito e a vida dos direitos. 6. ed. atual. São Paulo: Revista dos Tribunais, 2004.

RÜDIGER, Dorothee Susanne. Teoria da flexibilização do direito do trabalho: uma tentativa de contextualização histórica,Prim@ Facie - ano 3, n. 4, jan./jun. 2004, p. 29-57.

SEN, Amartya K. Desenvolvimento como liberdade. Trad. Laura Teixeira Mota. São Paulo: Companhia das Letras, 2005.

Trabalho enviado em 28 de setembro de 2018

Aceito em 01 de fevereiro de 2019 